\title{
Dimensões dos arcos dentários na má oclusão Classe II, divisão 1, com deficiência mandibular
}

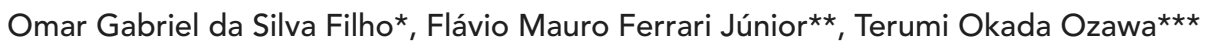

\begin{abstract}
Resumo
Objetivo: identificar alterações dimensionais nos arcos dentários superior e inferior na má oclusão Classe II, divisão 1, com deficiência mandibular (Padrão esquelético II). Métodos: 48 pacientes com má oclusão Classe II, igualmente divididos quanto ao gênero, foram comparados com 51 indivíduos com oclusão normal, sendo 22 do gênero masculino e 29 do gênero feminino. Todos os 99 indivíduos estavam no estágio de dentadura permanente, com os segundos molares permanentes irrompidos ou em irrupção, com idade média de 12 anos e 5 meses (desvio-padrão de 1 ano e 3 meses), numa faixa etária oscilando entre 11 anos e 4 meses e 20 anos. Conclusão: os resultados permitem concluir que, na má oclusão Classe II, divisão 1 com deficiência mandibular, o arco dentário superior encontra-se alterado, mostrando-se atrésico e mais longo, enquanto o arco dentário inferior é pouco influenciado pela discrepância sagital de Classe II.
\end{abstract}

Palavras-chave: Má oclusão de Angle Classe II. Arco dentário.

\section{INTRODUÇÃO E REVISÃO DE LITERATURA}

É difícil determinar a incidência da má oclusão Classe II na população mundial com base na literatura disponivel, uma vez que os critérios metodológicos empregados, bem como a formação dos pesquisadores, variam muito entre os diversos estudos, além das possíveis interferências étnicas. Para se ter ideia, a incidência de má oclusão Classe II, divisão 1, na literatura oscila entre $8,6 \%{ }^{3}$ e $33,7 \%{ }^{12}$. O mesmo ocorre para a divisão 2 , cuja epidemiologia estendese de $0,6 \%^{3}$ a $6,7 \% \%^{17}$. Uma análise oclusal criteriosa feita por ortodontistas revelou que, no Brasil, a má oclusão Classe II alcança uma porcentagem de quase $50 \%$ das más oclusões nas dentaduras decídua ${ }^{24} \mathrm{e}$ mista ${ }^{25}$, levando em consideração a chave de caninos decíduos ou de pré-molares, na dependência do estágio do desenvolvimento da oclusão.

A má oclusão Classe II refere-se a um erro sagital entre os arcos dentários e pode manifestar-se em faces normais (Padrão esquelético I) e em faces com deficiência mandibular (Padrão esquelético II). De acordo com a análise facial, em torno de 15\% da população escolar de Bauru/SP no estágio de dentadura mista manifesta discrepâncias esqueléticas acompanhando a Classe II, das quais 11,5\% apresentam características peculiares da divisão 1 , enquanto os $3,5 \%$ apresentam características da divisão $2^{25}$. Em síntese, a má oclusão Classe II é frequente na população e manifesta-se tanto em Padrão esquelético I quanto em Padrão esquelético II (Fig. 1).

* Ortodontista do Hospital de Reabilitação de Anomalias Craniofaciais da Universidade de São Paulo (HRAC-USP). Coordenador do Curso de Ortodontia Preventiva e Interceptiva da Sociedade de Promoção Social do Fissurado Lábio Palatal (PROFIS). Professor do Curso de Especialização de Ortodontia da PROFIS, Bauru/SP.

** Professor do Curso de Ortodontia Preventiva e Interceptiva da PROFIS, Bauru/SP.

*** Ortodontista do HRAC-USP. Professora do Curso de Ortodontia Preventiva e Interceptiva da PROFIS. Professora do Curso de Especialização em Ortodontia da PROFIS, Bauru/SP. 

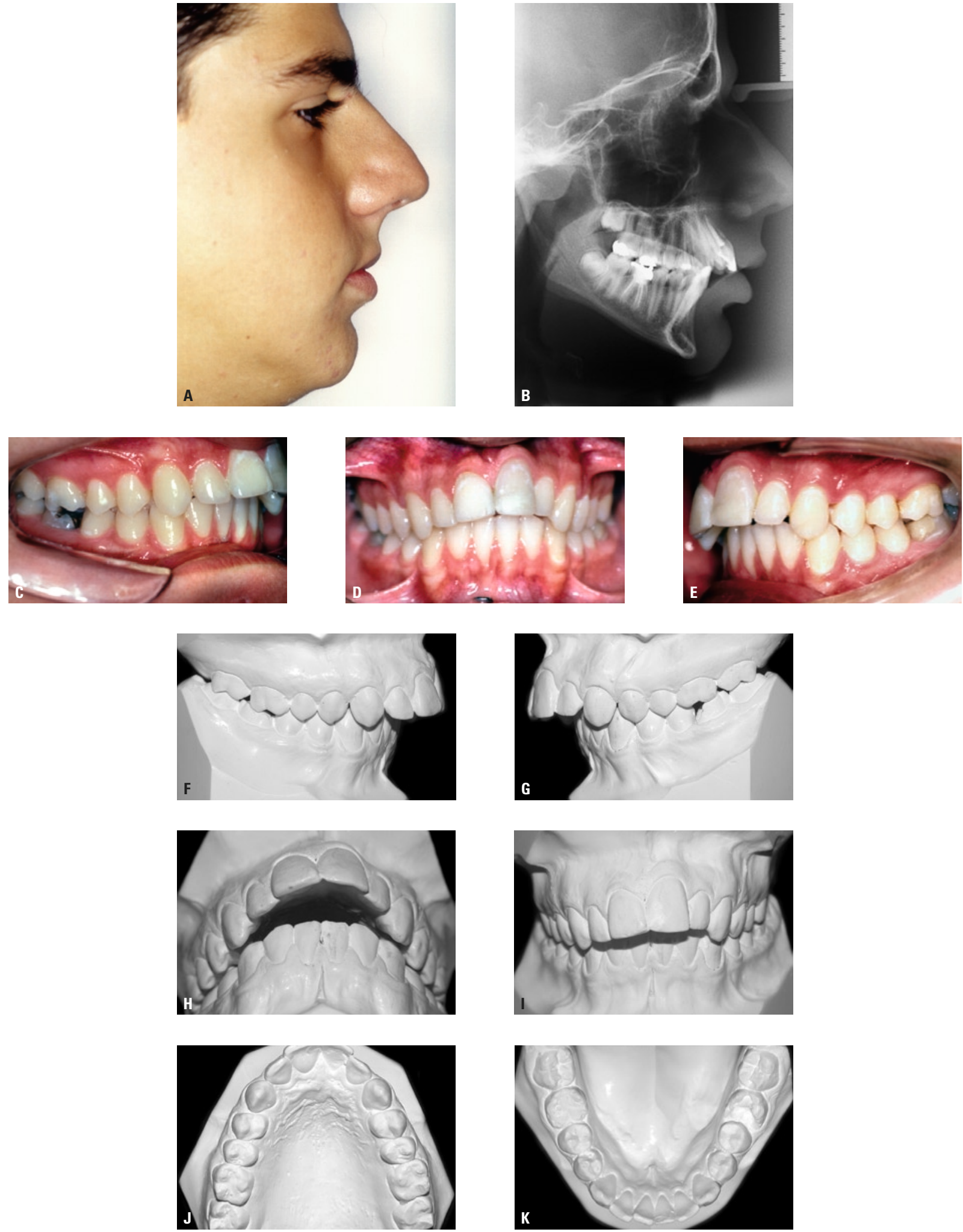

FIGURA 1 - 0 diagnóstico clínico da má oclusão é elaborado pelo somatório das análises facial (A), radiográfica (B) e oclusal (C-K). A interpretação morfológica dessas análises leva ao diagnóstico da má oclusão Classe II, divisão 1, com deficiência mandibular (Padrão esquelético II). 
Antes da disseminação da cefalometria como instrumento de diagnóstico ortodôntico, já se admitia que a deficiência mandibular contribuía para a discrepância ântero-posterior de Classe II, o que se confirmou numericamente com a chegada da cefalometria ${ }^{4,5,6,7,9,14,20,21,31}$. Em decorrência do diagnóstico da deficiência mandibular, admite-se a Ortopedia Funcional dos Maxilares e a Cirurgia Ortognática como coadjuvantes quase indispensáveis da mecanoterapia ortodôntica, na tentativa de melhorar a participação sagital da mandíbula na face e corrigir a Classe II. A experiência com o avanço mandibular ortopédico ou cirúrgico tem alertado os ortodontistas para a mordida cruzada posterior que advém com o reposicionamento anterior da mandíbula. Essa condição, na realidade, reflete a atresia presente no arco dentário superior em más oclusões Classe II com deficiência mandibular, Padrão esquelético II (Fig. 2).

Como sugerem as figuras 1 e 2 , além do erro sagital interarcos dentários e, ocasionalmente, entre as bases apicais, existem alterações identificáveis na morfologia dos arcos dentários que diferenciam uma má oclusão Classe II. A literatura pertinente à morfologia dos arcos dentários superior e inferior na má oclusão Classe II está resumida no quadro 1 . Ela sugere que o arco dentário superior mostra-se vulnerável à discrepância sagital de Classe II. O estreitamento do arco dentário superior, por exemplo, pode ser interpretado como uma compensação transversal do arco dentário superior ao retroposicionamento mandibular e induz o clínico a aumentar as dimensões transversais do arco dentário superior em algum estágio do tratamento da Classe $\mathrm{II}^{6,8,29}$, quando se pretende o avanço mandibular. O envolvimento do arco dentário superior na má oclusão Classe II tem sido constatado desde a dentadura decídua ${ }^{32}$, ou desde os 7 anos de idade ${ }^{1,18}$, e não se autocorrige até as dentaduras mista ${ }^{6,29} \mathrm{e}$ permanente ${ }^{8,18}$. Portanto, os estudos longitudinais demonstram que as alterações dimensionais do arco dentário superior nas más oclusões Classe II manifestam-se desde a dentadura decídua ${ }^{6,8,18,29}$ e não se autocorrigem.
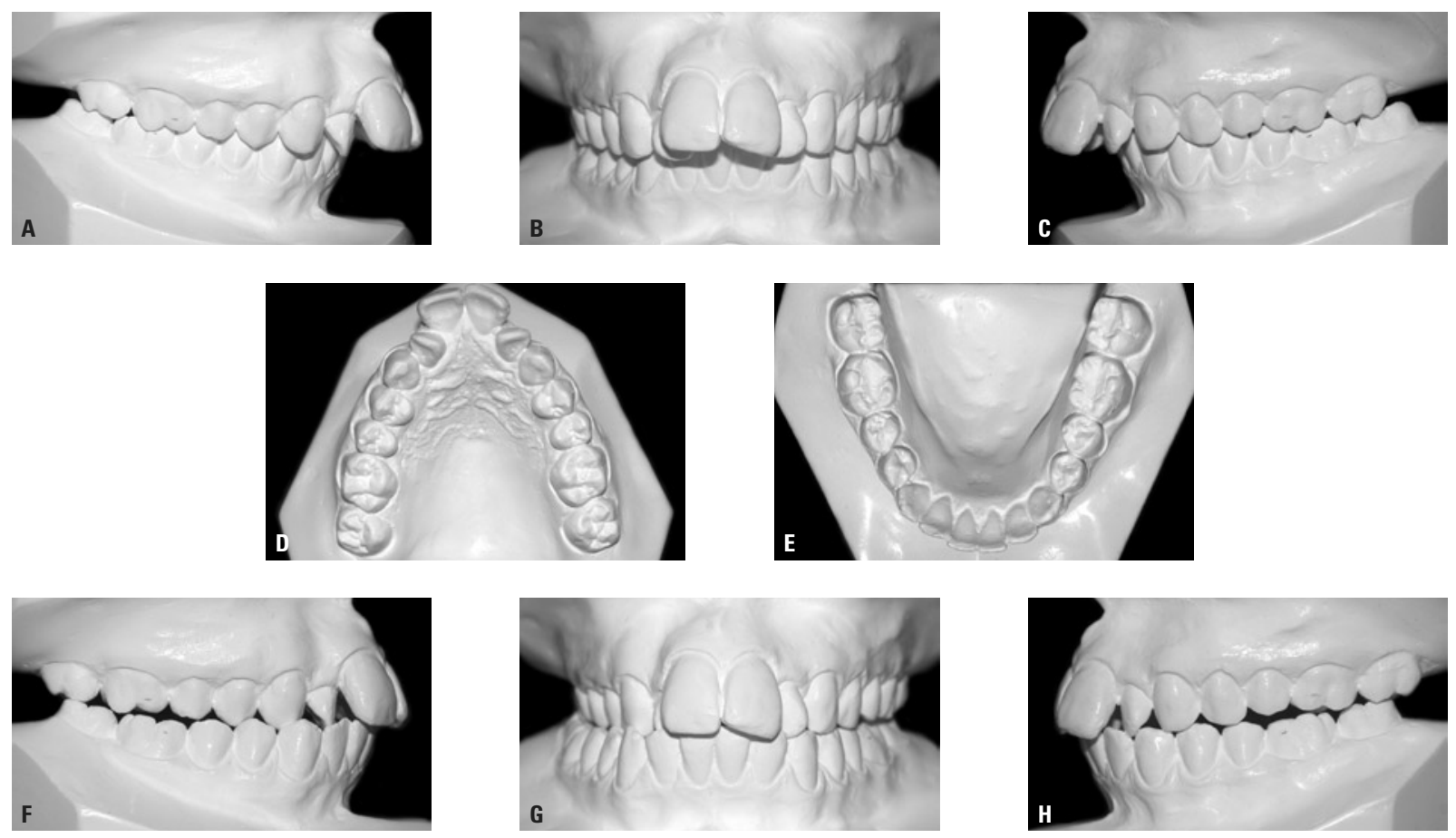

FIGURA 2 - Modelos de gesso representando a má oclusão Classe II divisão 1 (A-E). A simulação de correção da Classe II (F, G, H) com o avanço do arco dentário inferior denuncia a deficiência transversal da maxila, que se manifesta em forma de mordida cruzada posterior. 


\begin{tabular}{|c|c|c|c|c|c|c|}
\hline \multirow{2}{*}{ autor } & \multicolumn{2}{|c|}{ amostra com Classe II } & \multicolumn{2}{|c|}{ amostra controle } & \multirow{2}{*}{ etnia } & \multirow{2}{*}{ medidas } \\
\hline & idade & $\mathbf{n}$ & idade & n & & \\
\hline $\begin{array}{l}\text { Baccetti et al. }{ }^{6} \\
\text { (1997) }\end{array}$ & $\begin{array}{l}\text { 5a } 8 \mathrm{~m} \mathrm{e} \\
8 \mathrm{a} 1 \mathrm{~m} \\
\text { (estudo } \\
\text { longitudinal) }\end{array}$ & 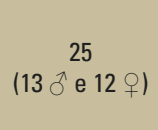 & $\begin{array}{l}\text { 5a } 5 \mathrm{~m} \mathrm{e} \\
\text { 7a } 8 \mathrm{~m} \\
\text { (estudo } \\
\text { longitudinal) }\end{array}$ & 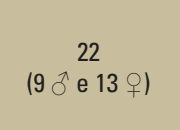 & $\begin{array}{l}\text { Universidade } \\
\text { de Michigan/ } \\
\text { Universidade } \\
\text { de Florença }\end{array}$ & $\begin{array}{l}\text { transversais } \\
\text { (arcos dentários } \\
\text { superior e inferior) }\end{array}$ \\
\hline $\begin{array}{l}\text { Bishara et al. }{ }^{8} \\
\text { (1996) }\end{array}$ & 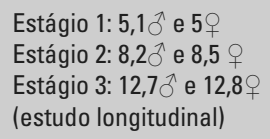 & 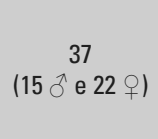 & 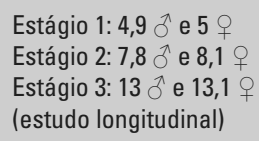 & 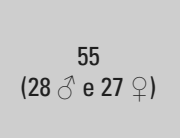 & $\begin{array}{l}\text { Universidade } \\
\text { de lowa }\end{array}$ & $\begin{array}{l}\text { sagitais e transversais } \\
\text { (arcos dentários } \\
\text { superior e inferior) }\end{array}$ \\
\hline $\begin{array}{l}\text { Bushang et al. }{ }^{10} \\
\text { (1994) }\end{array}$ & $\begin{array}{l}\text { Entre } 17 / 25 \text { anos } \\
\text { Entre } 25 / 35 \text { anos } \\
\text { Acima de } 35 \text { anos }\end{array}$ & $\begin{array}{c}145 \mathrm{P}+ \\
121 \mathrm{Cl} . \mathrm{II} / 2 \\
24 \mathrm{Cl} . \mathrm{II} / 1\end{array}$ & $\begin{array}{l}\text { Entre } 17 / 25 \text { anos } \\
\text { Entre } 25 / 35 \text { anos } \\
\text { Acima de } 35 \text { anos }\end{array}$ & $241+$ & ---- & $\begin{array}{l}\text { sagitais, transver- } \\
\text { sais e condição dos } \\
\text { incisivos }\end{array}$ \\
\hline $\begin{array}{l}\text { Lux et al. }{ }^{18 *} \\
(2003)\end{array}$ & $\begin{array}{l}\text { Dos } 7 \text { aos } 15 \text { anos } \\
\text { (estudo longitudinal) }\end{array}$ & 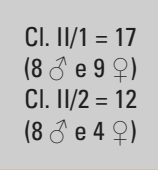 & $\begin{array}{l}\text { Dos } 7 \text { aos } 15 \text { anos } \\
\text { (estudo longitudinal) }\end{array}$ & $\begin{array}{c}\mathrm{Cl} . \mathrm{I}=37 \\
(19 \text { ô e } 18 \text { }) \\
\text { Oclusão } \\
\text { normal = } 18 \\
(10 \text { ô e } 8 \text { + })\end{array}$ & $\begin{array}{l}\text { Belfast Growth } \\
\text { Study }\end{array}$ & $\begin{array}{l}\text { transversal } \\
\text { (arcos dentários } \\
\text { superior e inferior) }\end{array}$ \\
\hline $\begin{array}{l}\text { Sayin e } \\
\text { Turkkahraman }{ }^{22} \\
\text { (2004) }\end{array}$ & 16,07 anos & 30 우 & 19,17 anos & 30 우 & $\begin{array}{l}\text { Universidade } \\
\text { de Suleyman } \\
\text { Demirel, } \\
\text { Turquia }\end{array}$ & $\begin{array}{l}\text { transversais } \\
\text { (arcos dentários e } \\
\text { alveolares, superior e } \\
\text { inferior) }\end{array}$ \\
\hline $\begin{array}{l}\text { Staley et al. } .^{28} \\
(1985)\end{array}$ & $\begin{array}{l}22,1 \text { anos } \hat{\sigma} \\
18 \text { anos }+\end{array}$ & 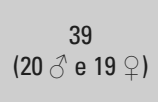 & $\begin{array}{l}20,6 \text { anos }{ }^{\pi} \\
16 \text { anos } q\end{array}$ & $\begin{array}{c}36 \\
\left(19 \text { ô }^{1} \text { e } 17 \text { 우 }\right)\end{array}$ & $\begin{array}{l}\text { Universidade } \\
\text { de lowa }\end{array}$ & $\begin{array}{l}\text { transversais } \\
\text { (arcos dentários } \\
\text { superior e inferior) }\end{array}$ \\
\hline $\begin{array}{l}\text { Uysal et al. }{ }^{30} \\
\text { (2005) }\end{array}$ & $\begin{array}{l}17,2 \text { anos (Cl. II/1) } \\
18,5 \text { anos (CI. II/2) }\end{array}$ & 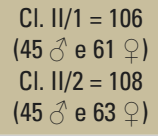 & 21,6 anos & $\begin{array}{c}150 \\
\left(72 \text { ôn }^{1} \text { e } 78 \text { 우 }\right)\end{array}$ & $\begin{array}{l}\text { Universidade } \\
\text { de Selcuk, } \\
\text { Turquia }\end{array}$ & $\begin{array}{l}\text { transversais } \\
\text { (arcos dentários } \\
\text { superior e inferior) }\end{array}$ \\
\hline $\begin{array}{l}\text { Walkow e Peck }{ }^{33} \\
\text { (2002) }\end{array}$ & 12,4 anos & $\begin{array}{c}23 \mathrm{Cl} . \mathrm{II} / 2 \\
(20 \text { ○े e } 3 \text { + })\end{array}$ & 12,4 anos & $\begin{array}{c}46 \\
\text { (pareados com } \\
\text { o grupo } \mathrm{Cl} . \mathrm{II} / 2 \text { ) }\end{array}$ & $\begin{array}{l}\text { Universidade } \\
\text { de Harvard }\end{array}$ & transversal \\
\hline
\end{tabular}

QUADRO 1 - Estudos oriundos da literatura referente ao comportamento dos arcos dentários na má oclusão Classe II. Em comum, a metodologia envolve modelos de gesso (* A metodologia incluiu também telerradiografia frontal).

Os estudos com dentadura permanente mostram influência da relação sagital entre aos arcos dentários na relação intra-arco. Buschang et al. ${ }^{10}$ encontraram o arco dentário superior mais estreito e mais longo em mulheres adultas com Classe II, divisão 1, na faixa etária entre 17 e 68 anos. Sayin e Turkkahraman $^{22}$ encontraram atresia somente nas larguras inter-segundos pré-molares e intermolares superiores e aumento na largura intercaninos inferiores em mulheres com Classe II, divisão 1, na dentadura permanente, com idade média de 16 anos. Staley et al. ${ }^{28}$ demonstram atresia do arco dentário superior nas distâncias intercaninos e intermolares na má oclusão Classe II, sem alteração dimensional na largura do arco dentário inferior, na dentadura permanente, em homens e mulheres adultos jovens. Uysal et al. ${ }^{30}$ encontraram atresia nas dimensões transversais do arco dentário superior e nas larguras interpré-molares e intermolares inferiores de pacientes adultos jovens com má oclusão Classe II, divisão 1 .

Os estudos também mostram que o arco dentário inferior é mais vulnerável ao erro sagital de Classe II nas más oclusões divisão 2. Quando Uysal et al. ${ }^{30}$ compararam más oclusões Classe II, divisões 1 e 2, encontraram que as larguras intercaninos e interpré-molares inferiores foram mais estreitas, enquanto a largura intermolares superiores foi maior na divisão 2 em relação à divisão 1 . Buschang et al. ${ }^{10}$ encontraram uma menor distância intercaninos e intermolares inferiores na divisão 2 em relação à divisão 1 e à Classe I. Walkow e Peck ${ }^{33}$ encontraram uma distância intercaninos inferiores mais estreita 
na divisão 2, com sobremordida profunda, em relação à divisão 1 .

A redução das dimensões transversais do arco dentário superior na má oclusão Classe II, divisão 1, tem suscitado polêmica quanto à sua etiologia estrutural. Staley et al. ${ }^{28}$ sugerem que essa atresia deve-se ao envolvimento da base óssea, portanto, de caráter esquelético, concordando com os dados de telerradiografias frontais de Alarashi et al. ${ }^{1}$ e de Lux et al. ${ }^{18}$, enquanto Sayin e Turkkahraman ${ }^{22}$ atribuem a atresia do arco dentário superior ao envolvimento dentário apenas, já que não encontraram diferença na largura alveolar entre mulheres adultas com relação de Classe I e Classe II.

O presente estudo avaliou o comportamento transversal e sagital dos arcos dentários superior e inferior na má oclusão Classe II, divisão 1, com deficiência mandibular (Padrão esquelético II), no estágio de dentadura permanente, em ambos os gêneros.

\section{MATERIAL E MÉTODOS \\ Material}

O grupo experimental foi constituído de modelos de gesso dos arcos dentários superior e inferior de 48 pacientes com má oclusão Classe II, divisão 1, com deficiência mandibular (Padrão esquelético II), não tratados, igualmente divididos quanto ao gênero, com idades variando entre 11 anos e 4 meses e 18 anos e 4 meses. $\mathrm{O}$ grupo experimental obedeceu aos seguintes critérios de seleção: (a) dentadura permanente, com os segundos molares permanentes em irrupção ou irrompidos; (b) má oclusão Classe II, divisão 1, com discrepância sagital simétrica de, pelo menos, 1/2 cúspide de pré-molares; (c) etnia brasileira; e (d) não submetidos a nenhuma intervenção ortodôntica. Portanto, os critérios morfológicos de inclusão na amostra foram a relação interarcos e a deficiência mandibular (Padrão esquelético II).

O grupo controle foi composto de modelos de gesso dos arcos dentários superior e inferior de 51 indivíduos com oclusão considerada "normal" e face harmoniosa (Padrão esquelético I), sendo 29 do gênero feminino e 22 do gênero masculino, numa faixa etária compreendida entre 11 e 20 anos. A idade média para a amostra total (grupo experimental e grupo controle) foi de 12 anos e 5 meses, com desvio-padrão de 1 ano e 3 meses.

Os modelos de gesso fazem parte do acervo do curso de especialização em Ortodontia do Hospital de Reabilitação de Anomalias Craniofaciais da Universidade de São Paulo, Bauru/SP.

\section{Métodos}

As medidas transversais e sagitais dos arcos dentários foram obtidas a partir de fotocópias dos modelos de gesso. Os modelos de gesso dos arcos dentários superior e inferior dos grupos controle e experimental foram colocados com as superfícies oclusais dos dentes voltadas para a parte central da prancha de vidro de uma máquina impressora da Xerox (Connecticut, EUA), sendo obtidas as fotocópias. Os modelos foram mantidos de tal forma que o plano oclusal permanecia paralelo à prancha de vidro. Pesquisas evidenciam ausência de distorções nas imagens de fotocópias dos modelos, dando credibilidade ao método ${ }^{2,19,27}$.

Sobre as fotocópias dos modelos, foram medidas as distâncias transversais (intercaninos, interprimeiros pré-molares, intersegundos pré-molares e interprimeiros molares) e a distância sagital, determinada pelo ponto médio entre os incisivos centrais e o ponto médio de uma linha tangente à superfície distal dos primeiros molares (Fig. 3).

A partir dessas medidas, foram obtidas as médias

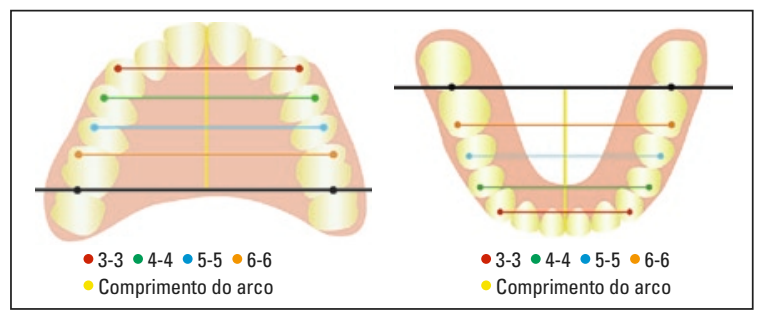

FIGURA 3 - A avaliação quantitativa dos arcos dentários superior e inferior foi obtida pela medição das distâncias transversais intercaninos (3-3), interprimeiros pré-molares (4-4), intersegundos pré-molares (5-5), interprimeiros molares (6-6) e da distância sagital (comprimento do arco). 
e os desvios-padrão para as distâncias transversais (3-3, 4-4, 5-5 e 6-6) e sagital (comprimento do arco) para os arcos dentários superior e inferior, em ambos os grupos de modelos - grupo experimental (má oclusão Classe II, divisão 1) e grupo controle (oclusão normal).

Com o objetivo de verificar a confiabilidade das medidas obtidas, as medições foram repetidas por dois avaliadores em alguns pares de modelos de gesso selecionados aleatoriamente. As medições foram repetidas com um intervalo de uma semana. Em todas as medições, o erro do método se mostrou próximo de $0,5 \mathrm{~mm}$, o que confere um caráter de alta confiabilidade às medidas obtidas pela metodologia escolhida para este estudo.

\section{RESULTADOS E DISCUSSÃO}

Os 99 pares de modelos de gesso avaliados na presente pesquisa encontravam-se no estágio de dentadura permanente, com os segundos molares permanentes em irrupção ou irrompidos, numa faixa etária compreendida entre 11 e 20 anos (idade média de 12 anos e 5 meses). Quarenta e oito modelos representavam a má oclusão Classe II, divisão 1, e os demais 51 modelos eram representativos de oclusão normal. A característica mais consistente da amostra experimental é a padronização em função do diagnóstico ortodôntico: má oclusão Classe II, divisão 1, com deficiência mandibular (Padrão esquelético II). A escolha da dentadura permanente deveu-se ao fato das dimensões transversais e sagitais dos arcos dentários estarem praticamente definidas e por ser essa a idade em que muitos pacientes procuram tratamento ortodôntico. Os estudos longitudinais sugerem que as dimensões dos arcos dentários tendem à estabilidade depois dos 13 anos de idade nas meninas e depois dos 16 anos nos meninos $7,11,15,16,23$, embora as alterações dimensionais nos arcos dentários, com influência no posicionamento dentário intra-arco, sejam imprevisíveis e possam ocorrer sem um limite

TABELA 1 - Média (X), desvio-padrão (d.p.) e teste t de Student para as dimensões transversais e sagital dos arcos dentários superior e inferior no grupo com oclusão normal, segundo o gênero.

\begin{tabular}{|c|c|c|c|c|c|c|c|c|c|c|}
\hline \multirow{3}{*}{ dimensões } & \multicolumn{4}{|c|}{ arco dentário superior } & \multirow{3}{*}{$t$} & \multicolumn{4}{|c|}{ arco dentário inferior } & \multirow{3}{*}{$\mathbf{t}$} \\
\hline & \multicolumn{2}{|c|}{ masculino $(n=22)$} & \multicolumn{2}{|c|}{ feminino $(n=29)$} & & \multicolumn{2}{|c|}{ masculino $(n=22)$} & \multicolumn{2}{|c|}{ feminino $(n=29)$} & \\
\hline & $\mathrm{X}$ & d.p. & $\mathrm{X}$ & d.p. & & $X$ & d.p. & $\mathrm{X}$ & d.p. & \\
\hline ântero-posterior & 38,88 & 2,02 & 36,34 & 1,94 & $* *$ & 34,28 & 1,86 & 32,15 & 1,96 & ** \\
\hline intercaninos & 35,98 & 2,32 & 33,73 & 2,19 & $* *$ & 26,88 & 1,84 & 25,44 & 1,96 & ** \\
\hline inter $1^{\text {os }}$ pré-molares & 43,78 & 2,37 & 41,72 & 2,18 & ** & 35,51 & 2,15 & 33,62 & 2,16 & ** \\
\hline inter $2^{\text {os }}$ pré-molares & 49,37 & 2,96 & 46,88 & 2,34 & $* *$ & 41,23 & 2,42 & 39,86 & 2,42 & ** \\
\hline inter $1^{\text {os }}$ molares & 54,21 & 3,58 & 52,24 & 2,81 & * & 46,91 & 2,81 & 45,62 & 2,58 & * \\
\hline
\end{tabular}

** Significante ao nível de 1\%; * significante ao nível de $5 \%$.

TABELA 2 - Média (X), desvio-padrão (d.p.) e teste t de Student para as dimensões transversais e sagital dos arcos dentários superior e inferior no grupo com Classe II, segundo o gênero.

\begin{tabular}{|c|c|c|c|c|c|c|c|c|c|c|}
\hline \multirow{3}{*}{ dimensões } & \multicolumn{4}{|c|}{ arco dentário superior } & \multirow{3}{*}{$\mathbf{t}$} & \multicolumn{4}{|c|}{ arco dentário inferior } & \multirow{3}{*}{$\mathbf{t}$} \\
\hline & \multicolumn{2}{|c|}{ masculino $(n=24)$} & \multicolumn{2}{|c|}{ feminino $(n=24)$} & & \multicolumn{2}{|c|}{ masculino $(n=24)$} & \multicolumn{2}{|c|}{ feminino $(n=24)$} & \\
\hline & $X$ & d.p. & $X$ & d.p. & & $\mathrm{X}$ & d.p. & $X$ & d.p. & \\
\hline ântero-posterior & 41,33 & 2,92 & 41,18 & 2,36 & n.s. & 35,19 & 3,05 & 34,96 & 1,52 & n.s. \\
\hline intercaninos & 34,25 & 2,92 & 32,91 & 1,88 & n.s. & 27,32 & 2,14 & 26,12 & 1,78 & * \\
\hline inter $1^{\text {ss }}$ pré-molares & 39,58 & 2,43 & 37,30 & 2,11 & $* *$ & 34,35 & 2,59 & 32,56 & 2,36 & * \\
\hline inter $2^{\text {os }}$ pré-molares & 44,25 & 3,55 & 42,54 & 2,48 & n.s. & 40,22 & 2,81 & 38,07 & 3,19 & $*$ \\
\hline inter $1^{\text {os }}$ molares & 49,77 & 2,53 & 17,15 & 2,09 & $* *$ & 45,06 & 2,33 & 43,79 & 2,81 & n.s. \\
\hline
\end{tabular}

n.s. = não significante; ${ }^{* *}$ significante ao nível de $1 \%{ }^{*}$ significante ao nível de $5 \%$. 
etário até mesmo em oclusões normais ${ }^{26}$.

O propósito da presente pesquisa é determinar a influência que a discrepância sagital de Classe II com Padrão esquelético II exerce sobre as dimensões dos arcos dentários. Inicialmente, calculou-se a média $(\mathrm{X})$ e o desvio-padrão (d.p.) dos valores obtidos para as medidas transversais e sagital dos arcos dentários superior e inferior dos dois grupos amostrais (experimental e controle), separando-os por gênero. Foi também aplicado o teste $t$ de Student, para se estabelecer a presença ou não do dimorfismo sexual. Esses valores estão expressos nas tabelas 1 e 2 .

A análise da tabela 1 deixa claro que, na amostra com oclusão normal, as dimensões dos arcos dentários superiores e inferiores exibiram dimorfismo sexual em todas as grandezas examinadas, com valores maiores para o gênero masculino, em torno de 2,25mm para o arco dentário superior e 1,6mm para o arco dentário inferior. Isso não nos surpreende, pois os trabalhos que analisam as dimensões dos arcos dentários têm mostrado valores maiores para os homens ${ }^{11,15,16}$. No entanto, esse dimorfismo sexual não permaneceu tão evidente no grupo com má oclusão Classe II (Tab. 2). O dimorfismo sexual mostrou-se com significância estatística apenas na região média dos arcos dentários, em duas medidas transversais no arco dentário superior (distância interprimeiros pré-molares e intermolares) e em três medidas transversais no arco dentário inferior (intercaninos, interprimeiros pré-molares e intersegundos pré-molares). A condição morfológica de Classe II diminui a influência do fator gênero na determinação das dimensões dos arcos dentários superior e inferior, sendo esse fenômeno mais evidente no arco dentário superior. Pode-se concluir, portanto, que o dimorfismo sexual esteve presente em todas as dimensões (tranversais e sagital) dos arcos dentários superior e inferior em indivíduos com oclusão normal e esteve presente em algumas dimensões transversais nos indivíduos com má oclusão Classe II. Em função do

TABELA 3 - Comparação estatística (teste t de Student) para os valores das dimensões transversais e sagital do arco dentário superior entre os grupos com oclusão normal e com Classe II, para os gêneros masculino e feminino.

\begin{tabular}{|c|c|c|c|c|c|c|c|c|c|c|}
\hline \multirow{3}{*}{ dimensões } & \multicolumn{4}{|c|}{ gênero masculino } & \multirow{3}{*}{$\mathbf{t}$} & \multicolumn{4}{|c|}{ gênero feminino } & \multirow{3}{*}{$\mathbf{t}$} \\
\hline & \multicolumn{2}{|c|}{ normal $(n=22)$} & \multicolumn{2}{|c|}{ Classe II $(n=24)$} & & \multicolumn{2}{|c|}{ normal $(n=29)$} & \multicolumn{2}{|c|}{ Classe II (n= 24) } & \\
\hline & $X$ & d.p. & $x$ & d.p. & & $x$ & d.p. & $x$ & d.p. & \\
\hline ântero-posterior & 38,88 & 2,02 & 41,33 & 2,92 & $* *$ & 36,34 & 1,94 & 41,18 & 2,36 & ** \\
\hline intercaninos & 35,98 & 2,32 & 34,25 & 2,92 & $*$ & 33,73 & 2,19 & 32,91 & 1,88 & n.s. \\
\hline inter $1^{\text {os }}$ pré-molares & 43,78 & 2,37 & 39,58 & 2,43 & ** & 41,72 & 2,18 & 37,30 & 2,11 & ** \\
\hline inter $2^{\text {os }}$ pré-molares & 49,37 & 2,96 & 44,25 & 3,55 & $* *$ & 46,88 & 2,34 & 42,54 & 2,48 & ** \\
\hline inter $1^{\text {os }}$ molares & 54,21 & 3,58 & 49,77 & 2,53 & $* *$ & 52,54 & 2,81 & 47,45 & 2,09 & ** \\
\hline
\end{tabular}

n.s. = não significante; ${ }^{*}$ significante ao nível de $5 \%$; ${ }^{* *}$ significante ao nível de $1 \%$.

TABELA 4 - Comparação estatística (teste t de Student) para os valores das dimensões transversais e sagital do arco dentário inferior entre os grupos oclusão normal e Classe II, para os gêneros masculino e feminino.

\begin{tabular}{|c|c|c|c|c|c|c|c|c|c|c|}
\hline \multirow{3}{*}{ dimensões } & \multicolumn{4}{|c|}{ gênero masculino } & \multirow{3}{*}{$\mathbf{t}$} & \multicolumn{4}{|c|}{ gênero feminino } & \multirow{3}{*}{$t$} \\
\hline & \multicolumn{2}{|c|}{ normal (n=22) } & \multicolumn{2}{|c|}{ Classe II $(n=24)$} & & \multicolumn{2}{|c|}{ normal $(\mathrm{n}=29)$} & \multicolumn{2}{|c|}{ Classe II (n= 24) } & \\
\hline & $X$ & d.p. & $\mathrm{X}$ & d.p. & & $X$ & d.p. & $X$ & d.p. & \\
\hline ântero-posterior & 34,28 & 1,86 & 35,19 & 3,05 & n.s. & 32,15 & 1,96 & 34,96 & 1,52 & ** \\
\hline intercaninos & 26,88 & 1,84 & 27,32 & 2,14 & n.s. & 25,44 & 1,96 & 26,12 & 1,78 & n.s. \\
\hline inter $1^{\text {os }}$ pré-molares & 35,51 & 2,15 & 34,35 & 2,59 & n.s. & 33,62 & 2,16 & 32,56 & 2,36 & n.s. \\
\hline inter $2^{\text {os }}$ pré-molares & 41,33 & 2,42 & 40,22 & 2,81 & n.s. & 39,86 & 2,42 & 38,07 & 3,19 & * \\
\hline inter $1^{\text {os }}$ molares & 46,91 & 2,81 & 45,06 & 2,33 & * & 45,62 & 2,58 & 43,79 & 2,81 & $*$ \\
\hline
\end{tabular}

n.s. = não significante; ${ }^{*}$ significante ao nível de $5 \%$; ** significante ao nível de $1 \%$. 


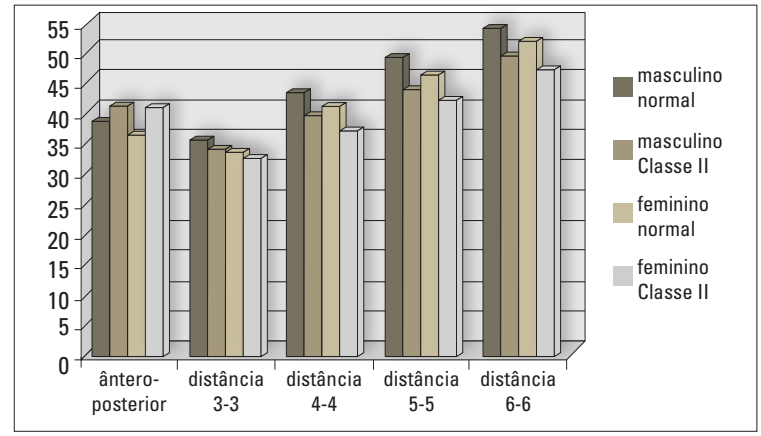

GRÁFICO 1 - Representação gráfica das dimensões sagital e transversais do arco dentário superior nos grupos com Classe II, divisão 1, e oclusão normal, para os gêneros masculino e feminino.

dimorfismo sexual presente em grande parte das dimensões avaliadas, a comparação do grupo normal com o grupo de má oclusão Classe II foi feita considerando o fator gênero. Essa comparação encontra-se nas tabelas 3 e 4 . Os gráficos 1 e 2 ilustram, para os arcos dentários superior e inferior, respectivamente, as medidas retratadas nas tabelas 1 e 2 .

A comparação entre os grupos com oclusão normal e com má oclusão Classe II, divisão 1, foi realizada para os arcos dentários superior (Tab. 3) e inferior (Tab. 4), separadamente. $\mathrm{O}$ arco dentário superior mostra que, excetuando-se a distância intercaninos para o gênero feminino, todas as medidas realizadas no arco dentário com má oclusão mostraram-se significativamente alteradas em relação ao padrão normal. Conclui-se, portanto, que a condição morfológica de Classe II, Padrão esquelético II, induz alterações nas dimensões e, consequentemente, na forma do arco dentário superior.

Com relação à distância sagital, a diferença estatisticamente significante entre os grupos normal e com Classe II delata um maior comprimento do arco dentário superior no grupo com má oclusão. Esse maior comprimento do arco deve ser atribuído à provável vestíbulo-versão, que é característica constante dos incisivos superiores na má oclusão Classe II, divisão 1.

Considerando-se as dimensões transversais (Tab. 3), o arco dentário superior está atrésico, configurando uma conformação triangular própria desse

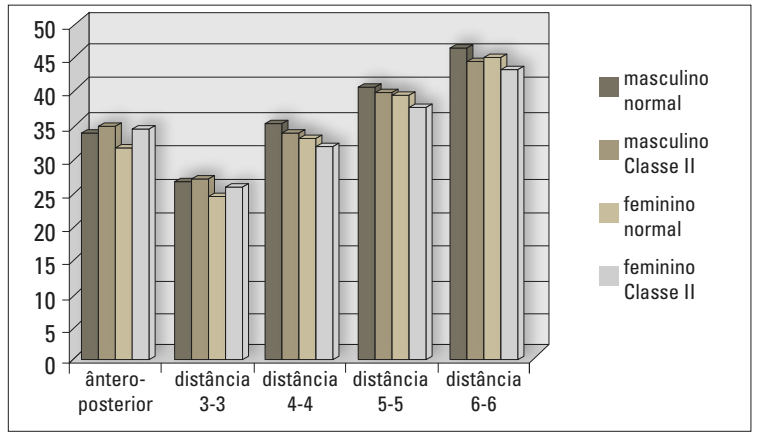

GRÁFICO 2 - Representação gráfica das dimensões sagital e transversais do arco dentário inferior nos grupos com Classe II, divisão 1, e oclusão normal, para os gêneros masculino e feminino.

arco nas más oclusões Classe II (Fig. 1, 2). A significância estatística só não foi alcançada na distância intercaninos superior para o gênero feminino. A tabela 5 quantifica o erro nas dimensões sagital e transversais do arco dentário superior na má oclusão Classe II, tendo como parâmetro o grupo normal. Esses números sugerem a quantidade média de expansão necessária no arco dentário superior durante a mecanoterapia para aproximá-lo das dimensões transversais do arco normal e acomodar transversalmente a mandíbula avançada em Classe I. Essa é a singularidade da má oclusão Classe II, divisão 1: a atresia do arco dentário superior não se faz acompanhar de mordida cruzada posterior, pelo menos como regra geral. A atresia do arco dentário superior na má oclusão Classe II, divisão 1, Padrão II, pode ser reflexo da atresia do complexo nasomaxilar, identificado em cefalometria frontal ${ }^{2,18}$. A cefalometria frontal mostra envolvimento dentomaxilar, sem alteração transversal na mandíbula e no arco alveolar inferior ${ }^{2,18}$.

TABELA 5 - Diferenças nas dimensões transversais e sagital do arco dentário superior entre os grupos com oclusão normal e com Classe II (em $\mathrm{mm}) .0$ valor representa a magnitude do erro no arco dentário superior na má oclusão Classe II.

\begin{tabular}{rccccc} 
& $\begin{array}{c}\text { ântero- } \\
\text { posterior }\end{array}$ & $\begin{array}{c}\text { inter- } \\
\text { caninos }\end{array}$ & $\begin{array}{c}\text { inter } \text { 1 }^{\text {s }} \\
\text { pré-molares }\end{array}$ & $\begin{array}{c}\text { inter } \mathbf{2}^{\text {os }} \\
\text { pré-molares }\end{array}$ & $\begin{array}{c}\text { inter- } \\
\text { molares }\end{array}$ \\
\hline masc. & $-2,45$ & 1,17 & 4,20 & 5,12 & 4,44 \\
fem. & $-4,84$ & 0,82 & 4,42 & 4,34 & 4,79 \\
média & $-3,64$ & 0,99 & 4,31 & 4,73 & 4,61 \\
\hline
\end{tabular}


A exemplo de outros pesquisadores (Quadro 1), Fröhlich ${ }^{13}$ estudou uma amostra longitudinal de 51 crianças desde a dentadura decídua até a dentadura permanente, numa faixa etária que se estendeu dos 6 aos 12 anos. Proclamou a persistência do erro sagital durante o período de acompanhamento, com aumento do trespasse horizontal e vertical depois da irrupção dos incisivos permanentes, o que concorda com outros estudos. No entanto, destoando da literatura, não encontrou diferença nas dimensões dos arcos dentários na Classe II. Essa contradição explica-se provavelmente por ter aglomerado más oclusões divisão 1 e divisão 2 na amostra. A presente pesquisa não endossa os resultados de Fröhlich ${ }^{13}$; pelo contrário, concorda com vários outros estudos que denunciam alterações na morfologia dos arcos dentários na má oclusão Classe II ${ }^{11,18,22,28,30}$.

A despeito dos possíveis fatores externos atrelados à atresia do arco dentário superior - como respiração bucal, hábitos prolongados de sucção, postura e função inadequadas de língua - não se pode omitir a possível adaptação transversal do arco dentário superior ao inferior, isso é, um mecanismo natural de compensação transversal do arco dentário superior ao retroposicionamento do arco dentário inferior. Esse é um fenômeno morfológico inerente à síndrome da Classe II, divisão 1, Padrão esquelético II. Portanto, a compensação dentária presente na má oclusão Classe II não se restringe à dimensão sagital e tampouco aos incisivos. A avaliação morfológica tridimensional em Ortodontia (Fig. 1, 2) fornece a interpretação completa e correta dos erros presentes na má oclusão Classe II, os quais manifestam-se nos três sentidos do espaço: sagital, transversal e vertical. A presente pesquisa foca o erro no sentido transversal e argumenta a indicação da expansão com intenção do preparo transversal do arco dentário superior para o avanço mandibular. A comprovação clínica da atresia do arco dentário superior, revelada mediante mordida cruzada posterior quando do avanço mandibular, implica em direcionar a mecanoterapia para uma relação lateral final equilibrada entre os arcos dentários superior e inferior depois do avanço mandibular, quer ortopédico (Fig. 4) ou cirúrgico.

O arco dentário inferior na má oclusão Classe II (Tab. 4) mostra alterações mais sutis. Essas alterações restringem-se ao maior comprimento e à redução nas dimensões interpré-molares e intermolares, com significância estatística apenas para o gênero feminino. O maior comprimento do arco dentário inferior deve-se à protrusão do incisivo inferior, o que caracteriza a compensação dentária inferior para o Padrão II. A grande variação na posição do incisivo
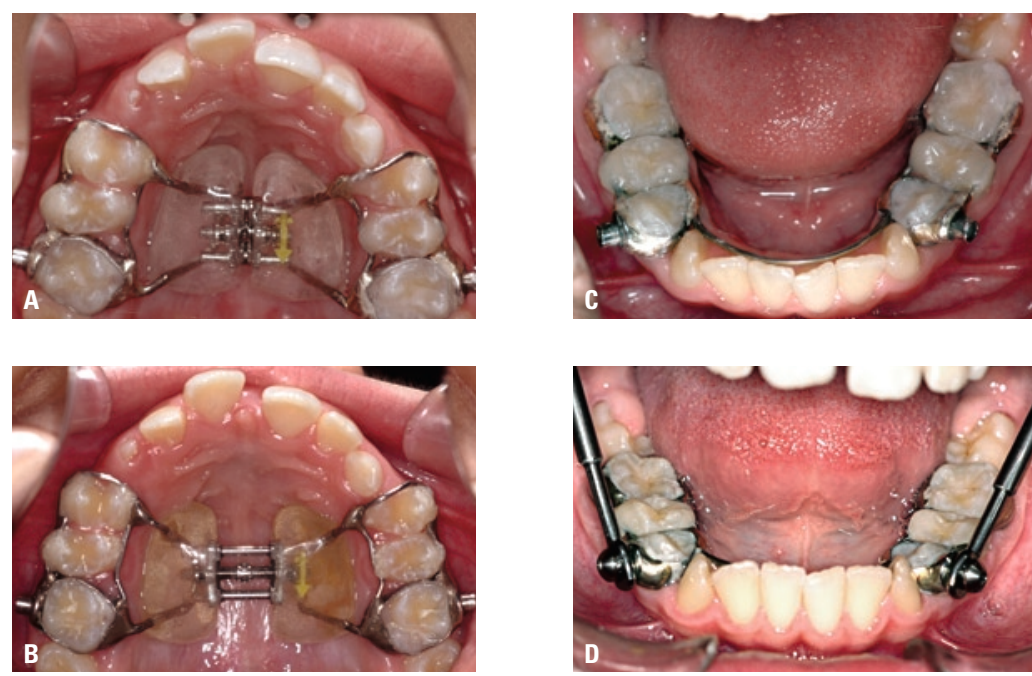

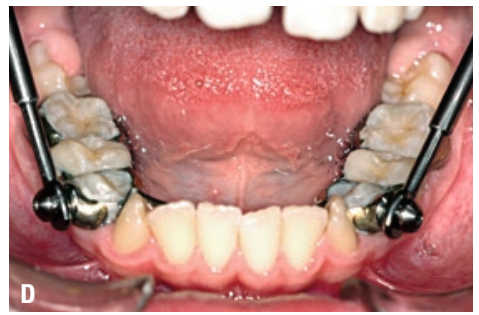

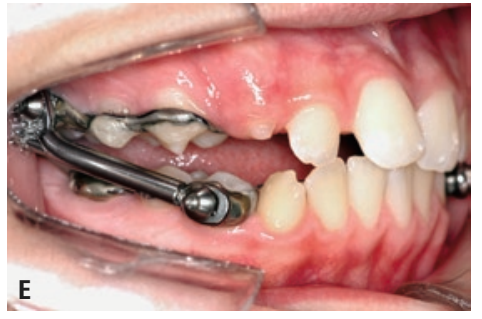

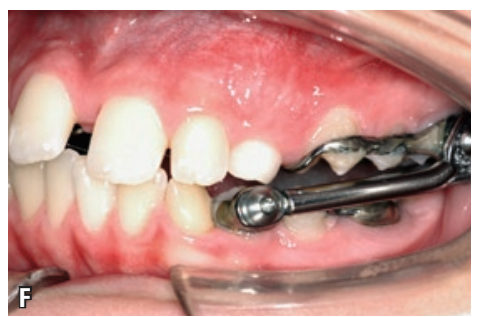

FIGURA 4 - Protocolo de tratamento da deficiência mandibular: descompensação transversal superior com a expansão rápida da maxila (A, B), imediatamente antes do avanço mandibular ortopédico contínuo (aparelho tipo Herbst) (C-F). 
TABELA 6 - Diferenças entre os arcos dentários superior e inferior na população com oclusão normal (em mm).

\begin{tabular}{|lccc|} 
& masculino & feminino & média \\
\hline ântero-posterior & 4,60 & 4,20 & 4,40 \\
\hline intercaninos & 9,10 & 8,29 & 8,70 \\
\hline inter $\mathbf{1}^{\text {os }}$ pré-molares & 8,27 & 8,10 & 8,20 \\
\hline inter ${ }^{\text {os }}$ pré-molares & 8,14 & 7,02 & 7,60 \\
intermolares & 7,30 & 6,62 & 6,70
\end{tabular}

inferior na má oclusão Classe II, que oscila da línguoversão até a vestíbulo-versão, pode ter camuflado a significância estatística para o gênero masculino. Isso explica o fato de que, mesmo na presença de uma tendência para um maior comprimento do arco inferior, a diferença entre os arcos superior e inferior registra um excesso para a má oclusão Classe II (Tab. 7) em relação à oclusão normal (Tab. 6).

A tendência de atresia na região posterior do arco dentário inferior pode ser entendida como uma acomodação do arco inferior à atresia do arco dentário superior. $\mathrm{O}$ comportamento do arco dentário inferior foi semelhante ao registrado por Uysal et al. ${ }^{30}$, que encontraram atresia na região posterior nas larguras interpré-molares e intermolares. Os presentes resultados diferem dos resultados de Sayin e Turkkahraman ${ }^{22}$ que, estudando mulheres com idade média de 16 anos, encontraram alteração para o arco dentário inferior apenas na largura intercaninos, maior para a Classe II, e de Fröhlich ${ }^{13}$, que não encontrou influência da Classe II no arco dentário inferior em crianças em crescimento.
TABELA 7 - Diferenças entre os arcos dentários superior e inferior na população com má oclusão Classe II (em mm).

\begin{tabular}{|lccc|}
\hline & masculino & feminino & média \\
\hline ântero-posterior & 6,14 & 6,22 & 6,20 \\
\hline intercaninos & 6,93 & 6,79 & 6,80 \\
\hline inter $\mathbf{1}^{\text {os }}$ pré-molares & 5,23 & 4,74 & 5,00 \\
\hline inter 20s pré-molares & 4,03 & 4,47 & 4,20 \\
intermolares & 4,71 & 3,66 & 4,20
\end{tabular}

A atresia do arco dentário superior na má oclusão Classe II, divisão 1, Padrão II, reflete na diferença entre as dimensões transversas dos arcos superior e inferior. Verifica-se, na tabela 6, que a diferença média entre a largura dos arcos dentários com oclusão normal decresce gradativamente de $8,7 \mathrm{~mm}$ na região de caninos para $6,7 \mathrm{~mm}$ na região de molares. Para a Classe II (Tab. 7), essa diferença é notoriamente menor, decrescendo de $6,8 \mathrm{~mm}$ para $4,2 \mathrm{~mm}$. Isto confirma a necessidade de expansão do arco dentário superior ao longo da mecanoterapia, para correção da má oclusão Classe II, quando se planeja $\mathrm{o}$ avanço mandibular.

\section{CONCLUSÕES}

Partindo da medição de modelos de gesso na dentadura permanente, os resultados permitem concluir que as dimensões do arco dentário superior em pacientes com má oclusão Classe II, divisão 1, Padrão esquelético II, encontram-se substancialmente alteradas. $\mathrm{O}$ arco dentário superior na Classe II mostra-se atrésico e mais longo.

\title{
Dimensions of the dental arches in the Class II, division 1, malocclusion with mandibular deficiency
}

\begin{abstract}
Aim: To determine the alterations of the upper and lower dental arches in the Class II, division 1, malocclusion with mandibular deficiency. Methods: Cast models of 48 individuals with Class II, division 1, malocclusion, equally matched according to gender, as well as of 51 individuals (22 males and 29 females) with normal occlusion were analyzed. All 99 subjects were in the permanent dentition with the second molars either erupted or erupting. The ages of all subjects ranged from 11 years 4 months to 20 years (mean age $=12$ years 5 months). Conclusion: We concluded that the upper dental arch is constricted and longer in the Class II, division 1, malocclusion with mandibular deficiency, while the lower arch is less influenced by Class II malocclusion.
\end{abstract}

Keywords: Angle Class II malocclusion. Dental arch. 


\section{REFERÊNCIAS}

1. ALARASHI, M. et al. Morphometric analysis of the transverse dentoskeletal features of Class II malocclusion in the mixed dentition. Angle Orthod., Appleton, v. 73, no. 1, p. 21-25, Feb. 2003.

2. ALMEIDA, R. R. Estudo comparativo da forma do arco dentário de brasileiros adultos brancos, amarelos e negros, utilizando o polinômio de $\mathbf{4}^{\circ}$ grau. 1972. Tese (Doutorado)Faculdade de Odontologia de Bauru, Universidade de São Paulo, Bauru, 1972.

3. ALMEIDA, R. R.; FÊEO, P. S.; MARTINS, D. R. Influência da fluoretação na prevalência de más oclusões. Estomat. Cult. Bauru, v. 4, n. 1, p. 35-42, 1970.

4. ANDERSON, D. L.; POPOVICH, F. Lower cranial height vs craniofacial dimensions in Angle Class II malocclusion. Angle Orthod., Appleton, v. 53, no. 3, p. 253-260, July 1983.

5. ANGLE, E. H. Treatment of malocclusion of the teeth Angle's system. Philadelphia: White Dental, 1907.

6. BACCETTI, T. et al. Early dentofacial features of Class II malocclusion: a longitudinal study from the deciduous through the mixed dentition. Am. J. Orthod. Dentofacial Orthop., St. Louis, v. 111, no. 5, p. 502-509, May 1997.

7. BISHARA, S. E. et al. Arch width changes from 6 weeks to 45 years of age. Am. J. Orthod. Dentofacial Orthop., St. Louis, v. 111, no. 4, p. 401-409, Apr. 1997.

8. BISHARA, S. E.; BAYATI, P.; JAKOBSEN, J. R. Longitudinal comparisons of dental arch changes in normal and untreated Class II division 1 subjects and their clinical implications. Am. J. Orthod. Dentofacial Orthop., St. Louis, v. 110, no. 5 , p. 483-489, Nov. 1996

9. BRODIE, A. G. The Angle concept of Class II, division 1 malocclusion. Angle Orthod., Appleton, v. 1, no. 4, p. 117-138, Oct. 1931.

10. BUSCHANG, P. H.; STROUD, J.; ALEXANDER, R. G. Differences in dental arch morphology among adult females with untreated Class I and Class II malocclusion. Eur. J. Orthod., London, v. 16, no. 1, p. 47-52, Feb. 1994

11. DeKOCK, W. H. Dental arch depth and width studied longitudinally from 12 years of age to adulthood. Am. J. Orthod. St. Louis, v. 62, no. 1, p. 56-66, July 1972.

12. ERICKSON, D. M.; GRAZIANO, F. W. Prevalence of malocclusion in seventh grade children in two North Carolina cities. J. Am. Dent. Assoc., Chicago, v. 73, no. 1, p. 124-127, July 1966.

13. FRÖHLICH, F. J. Changes in untreated Class II type malocclusions. Angle Orthod., Appleton, v. 32, no. 3, p. 167-179, July 1962.

14. HITCHCOCK, H. P. A cephalometric description of Class II, division 1 malocclusion. Am. J. Orthod., St. Louis, v. 63, no. 4, p. 414-423, Apr. 1973.

15. KNOTT, V. B. Longitudinal study of dental arch widths at four stages of dentition. Angle Orthod., Appleton, v. 42, no. 4, p. 387-394, Oct. 1972.

16. KNOTT, V. B. Size and form of the dental arches in children with good occlusion studied longitudinally from age 9 years to late adolescence. Am. J. Phys. Anthropol., Philadelphia, v. 19 p. 263-284, Sept. 1961.

17. KRZYPOW, A. B.; LIEBERMAN, M. A.; MODAN, M. Prevalence of malocclusion in young adults of various ethnic backgrounds in Israel. J. Dent. Res., Chicago, v. 54, no. 3, p. 605-608, May/ June 1975

18. LUX, C. J. et al. Dental arch widths and mandibular-maxillary base widths in Class II malocclusions between early mixed and permanent dentitions. Angle Orthod., Appleton, v. 73, no. 6, p. 674-685, Dec. 2003.

19. MAZAHERI, M. et al. Changes in arch form and dimensions of cleft patients. Am. J. Orthod., St. Louis, v. 60, no. 1, p. 19-32, July 1971.

20. McNAMARA JR., J. A. Components of Class II malocclusion in children 8-10 years of age. Angle Orthod., Appleton, v. 51, no. 3, p. 177-202, July 1981
21. OPPENHEIM, A. Prognathism from the anthropological and orthodontic viewpoints. Dent. Cosmos, Philadephia, v. 70, p. 1170-1184, Nov./Dec. 1928

22. SAYIN, M. O.; TURKKAHRAMAN, H. Comparison of dental arch and alveolar widths of patients with Class II division 1 malocclusion and subjects with Class I ideal occlusion. Angle Orthod. Appleton, v. 74, no. 3, p. 356-360, June 2004.

23. SILLMAN, J. H. Dimensional changes of the dental arches: longitudinal study from birth to 25 years. Am. J. Orthod., St. Louis, v. 50, no. 11, p. 824-842, Nov. 1964.

24. SILVA FILHO, O. G. et al. Epidemiologia da má oclusão na dentadura decídua. Ortodontia, São Paulo, v. 35, n. 1, p. 22-33, jan./mar. 2002

25. SILVA FILHO, O. G.; FREITAS, S. F.; CAVASSAN, A. O. Prevalência de oclusão normal e má oclusão em escolares da cidade de Bauru (São Paulo). Parte I: relação sagital. Rev. Odontol. Univ. São Paulo, São Paulo, v. 4, n. 2, p. 130-137, abr./jun. 1990.

26. SINCLAIR, P. M.; LITTLE, R. M. Maturation of untreated normal occlusions. Am. J. Orthod., St. Louis, v. 83, no. 2, p. 114-123, Feb. 1983.

27. SINGH, I. J.; SAVARA, B. S. A method for making tooth and dental arch measurements. J. Am. Dent. Assoc., Chicago, v. 69, p. 719-721, Dec. 1964

28. STALEY, R. N.; STUNTZ, W. R.; PETERSON, L. C. A comparison of arch widths in adults with normal occlusion and adults with Class II, division 1 malocclusion. Am. J. Orthod., St. Louis, v. 88 , no. 2, p. 163-169, Aug. 1985.

29. TOLLARO, I. et al. Role of posterior transverse interarch discrepancy in Class II, division 1 malocclusion during the mixed dentition phase. Am. J. Orthod. Dentofacial Orthop. St. Louis, v. 110, no. 4, p. 417-422, Oct. 1996.

30. UYSAL, T. et al. Dental and alveolar arch widths in normal occlusion, Class II division 1 and Class II division 2. Angle Orthod., Appleton, v. 75, no. 6, p. 941-947, Nov. 2005

31. VALE, D. M. V.; MARTINS, D. R. Avaliação cefalométrica das estruturas dento-esqueléticas em jovens portadores de Classe II, divisão 1, brasileiros, leucodermas e de origem mediterrânea. Ortodontia, São Paulo, v. 20, n. 1/2, p. 5-17, jan./dez. 1987.

32. VARRELA, J. Early development traits in Class II malocclusion. Acta Odontol. Scand., Stockholm, v. 56, no. 6, p. 375-377, Dec. 1998.

33. WALKOW, T. M.; PECK, S. Dental arch width in Class II division 2 deep-bite malocclusion. Am. J. Orthod. Dentofacial Orthop., St. Louis, v. 122, no. 6, p. 608-613, Dec. 2002.

Enviado em: setembro de 2006 Revisado e aceito: novembro de 2006

\section{Endereço para correspondência}

Omar Gabriel da Silva Filho

Setor de Ortodontia do HRAC-USP

Rua Silvio Marchione, 3-20 - Vila Universitária

CEP: 17.012-900 - Bauru/SP

E-mail: ortoface@travelnet.com.br 